This paper is published in the open archive of Mid Sweden University

DIVA http://miun.diva-portal.org

with permission of the publisher

Citation for the peer-reviewed published paper:

Pettersson G, Sjöberg J, Wågberg L, Höglund H. Increased joint-forming ability of ductile kraft pulp fibres by polyelectrolyte multilayer

treatment-Influence of refining and drying strategies. ; Nordic Pulp \&

Paper Research Journal. 2007;22(2):228-235.

URL to article at publishers site:

http://dx.doi.org/10.3183/NPPRJ-2007-22-02-p228-235 


\section{Increased joint-forming ability of ductile kraft pulp fibres by polyelectrolyte multilayer treatment - Influence of refining and drying strategies}

Gunilla Pettersson and Jessica C. Sjöberg, Mid Sweden University, Sundsvall, Sweden, Lars Wågberg, Royal Institute of Technology, KTH, Stockholm, Sweden, Hans Höglund, Mid Sweden University, Sundsvall, Sweden, Andreas Averheim, Luleå University of Technology, Luleå, Sweden

KEYWORDS: Adsorption, Interactions, Mechanical properties, Multilayer, Polyelectrolytes, Polymers, Pressurised HC refining, Sack paper, Surfaces

SUMMARY: In this study a sack paper furnish was used. It consisted of a high-consistency kraft pulp refined in either an atmospheric pressure or a pressurized system. The pulps were subsequently low-consistency refined in an Escher-Wyss laboratory refiner to 17.5-20.5 SR. Ordinary ISO sheets and freely dried sheets were manufactured from these pulp samples to serve as reference sheets. The laboratory sheets made of pulp from the pressurized system had a higher strain at break and tensile energy adsorption index but a lower tensile index than sheets made of pulp from a conventional atmospheric highconsistency refiner. These sheets were subject to a polyelectrolyte multilayer treatment to increase the interaction between the fibres, thus enhancing the paper strength properties. The polyelectrolyte multilayers (PEM) were applied by sequentially treating fibres from an unbleached kraft pulp for sack paper production with cationic starch and anionic carboxymethyl cellulose. The multilayer treatment was only applied to $50 \%$ of the stock and both ordinary ISO sheets and freely dried sheets were prepared with one and three layers of polyelectrolyte. Evaluation of the strength properties of the sheets showed that the addition of only one layer of starch increased strain at break, tensile index, tensile energy adsorption index, and out-of-plane properties measured as Scott-bond values. Using the multilayer technique created large increases in Scott-bond, a measure of the internal bonding of the sheets. The achieved effects were significantly larger than those usually achieved by applying starch alone to enhance the out-of plane strength properties. Also, the density increased considerably when the third layer was applied, for both ISO and freely dried sheets, though the tensile strength was enhanced significantly only in the freely dried sheets.

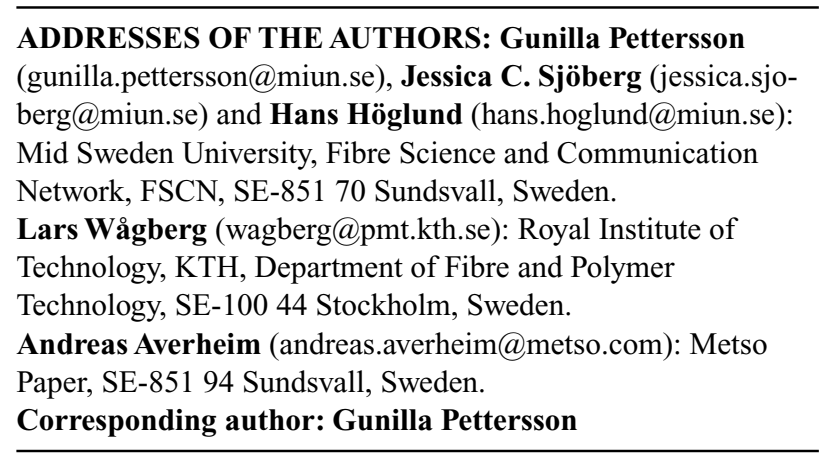

The paper sack market has been subject to continuous competition from bulk delivery systems, plastic sacks of various types, and intermediate-sized bulk containers. In many practical applications, it is very common for the material to be packed and blown into the sack under considerable pressure. To withstand these forces, the paper must be strong enough and highly ductile (i.e., with both a high tensile energy absorption index and strain at break), but also have low airflow resistance (Gurley) in order to prevent excess pressure building up in the sack.

High-consistency refining of kraft pulp under atmospheric conditions $\left(\mathrm{HC}_{\mathrm{atm}}\right.$ refining) is the current technical standard for producing extensible paper grades, such as sack and bag paper, because it improves the stretch characteristics of paper. When fibres are $\mathrm{HC}_{\text {atm }}$ refined, a closely packed structure of slip-planes (also known as micro compressions), are created in the fibres, a "concertina" like structure that appears along their length and induces good stretch properties in the paper (Miller 1998; Omholt 1999 and Hartler 1995).

Drying conditions are naturally also important in producing sack paper. For papers with medium-high strength, the stretch properties are largely determined by the shrinkage during drying, i.e., more shrinkage gives higher strain at break (Htun et al 1981; Page 1971 and Wahlström 1999). The transverse shrinkage of fibres, the extent of fibre-fibre joint formation and strength, and the axial compression resistance of fibres are three basic factors that determine the shrinkage. The extent of fibrefibre joint formation can be increased by making the fibres more flexible and by creating fines that adhere well to the fibre. The transverse shrinkage of fibres depends on how much the fibres swell in water: the more a fibre swells, the more it shrinks during drying. The degree to which a fibre swells can be increased by lowconsistency refining (LC refining). The contact area between fibres in a sheet will increase as the degree of swelling increases. At the point of contact between the fibres during drying, the transverse shrinkage of fibres compresses fibres crossing length-wise and creates micro compressions (Page 1971). Most important, however, is the axial compression resistance of fibres. This microcompressed structure is similar to the micro compressions that appear during HC treatment, but it should be noted that they are formed under different conditions (Page 1971).

An earlier study examined the $\mathrm{HC}$ refining of kraft pulp fibres under steam-pressurised $\left(\mathrm{HC}_{\text {press }}\right.$ refining) conditions in the $100-175^{\circ} \mathrm{C}$ temperature interval. It was found that these conditions could increase fibre curl and improve both strain at break and the tensile energy absorption index at a low level of airflow resistance, better than $\mathrm{HC}_{\mathrm{atm}}$ refining could (Sjöberg et al. 2005). However, the disadvantage of this refining technique is a reduced tensile index of the formed paper; and it was therefore felt important to evaluate different routes whereby to increase the tensile strength.

A common way to improve paper strength is to use 
additives, such as cationic starch, in the wet end of the paper machine, and rely on the high adsorption of the additives to the fibres, fines, and fillers to realise the full potential of the additive to enhance joint strength (Lindström and Wågberg 2005). However, the adsorption of an additive is limited by the charge of the fibres and the additive, together with the ionic strength of the solution (Wågberg 2000). This means that after addition of a certain amount of additives, the surfaces of the furnish components become saturated, further additions of strength additives thus end up in the white water, causing a range of problems (Wågberg and Kolar 1996). Alternative addition strategies are thus of interest, and it was recently shown (Wågberg et al. 2002, Zheng et al. 2006) that the polyelectrolyte multilayer (PEM) technique, developed by Decher (1997), can be applied successfully to wood fibres. PEM can be formed between almost any types of polyelectrolytes, as long as they carry opposite charges. Since pulp fibres carry a negative charge, the sequential addition of cationic and anionic polyelectrolytes to the fibres can rather easily be used to form a multilayer on the fibres of a desired thickness and softness. These multilayers will affect the dry strength properties of paper in different ways, depending on the polyelectrolytes used. Another alternative to improve the efficiency of the additives is to apply the additives in the form of polyelectrolyte complexes (Gärdlund et al. 2003, Hubbe 2005, Vainio et al. 2006). It was found that preformed complexes (Gärdlund et al 2003, Hubbe 2005) as well as in-situ formed complexes (Hubbe 2005) could significantly improve the tensile properties of sheets from treated fibres.

Given this background, we felt it was of interest to investigate whether PEM could be used to improve paper strength, using two polyelectrolytes already well known in the paper industry, namely, starch and carboxymethyl cellulose (CMC). This idea was supported by earlier studies indicating that the tensile index of Rapid Köthen laboratory sheets could be doubled when five layers of polyallylamine (PAH) and polyacrylicacid (PAA) were adsorbed onto the fibres at almost constant density, compared to sheets made of untreated pulp (Wågberg et al. 2002). By applying this strategy and forming sequential layers of cationic starch and CMC on fibres in different mechanical pulp-based sheets, it has also been found that out-of-plane properties of the sheets, measured as Scottbond values, were improved by almost $150 \%$ when only $20 \%$ of the furnish was PEM treated (Pettersson et al. 2006). In practice it will naturally be impossible to rinse the fibres between different layers and it has been demonstrated (Sandberg and Andreasson 2001) that a careful recharging of the fibres will allow for build up of PEM layer onto the fibres.

The present study examines the PEM treatment of highly extensible kraft pulp fibres produced by $\mathrm{HC}_{\text {press }}$ refining. Such treatment aims to improve the strength properties and simultaneously maintain most of the strain at break of the paper. The effect of drying conditions was also investigated, by comparing the properties of ordinary ISO sheets and freely dried sheets.

\section{Experimental}

\section{Pulp}

The pulp used for the refining experiments was a commercial unbleached, undried kraft pulp from the Mondi Packaging Dynäs AB pulp mill in Sweden. The pulp was taken from a twin-roll press prior to the HC refining stage in the mill. The pulp had a solids content of approximately $35 \%$ and a $\mathrm{pH}$ of approximately 9 . The wood mix used to produce the pulp comprised approximately 50\% pine and $50 \%$ spruce. The target kappa number was 43 , corresponding to a yield of around 50\%.

Trials of conventional $\mathrm{HC}_{\mathrm{atm}}$ refining and pressurised $\mathrm{HC}_{\text {press }}$ refining were carried out at the Metso Paper R\&D Centre in Sundsvall, Sweden. The pilot equipment is described in more detail in Sjöberg et al. (2005). One pulp sample from an $\mathrm{HC}_{\text {atm }}$ refining trial and two pulp samples from an $\mathrm{HC}_{\text {press }}$ refining trial, all of which consumed similar amounts of energy during refining, were chosen. The $\mathrm{HC}_{\mathrm{atm}}$ refined pulp was treated at $100^{\circ} \mathrm{C}, 415 \mathrm{kWh} / \mathrm{t}$, while the $\mathrm{HC}_{\text {press }}$ refined pulps were treated at $125^{\circ} \mathrm{C}, 353 \mathrm{kWh} / \mathrm{t}$ (denoted $\mathrm{HC}_{\text {press, }},{ }_{125}$ ) and $175^{\circ} \mathrm{C}, 376 \mathrm{kWh} / \mathrm{t}$ (denoted $\mathrm{HC}_{\text {press }},{ }_{175}$ ), respectively.

Pulps from the $\mathrm{HC}_{\text {atm }}$ and $\mathrm{HC}_{\text {press }}$ refining trials were then $\mathrm{LC}$ refined in an EscherWyss conical laboratory refiner at the SCA Technology Centre in Sundsvall, Sweden. In the refiner the pulps were circulated at 300 litres/min and carefully beaten for a predetermined period at a constant edge load, $1.26 \mathrm{Ws} / \mathrm{m}$, until the desired drainability (SR number) was reached. This resulted in the consumption of different amounts of energy for the LC refining of the different pulps. Pulp consistency during refining was around $2 \%$.

\section{Chemicals}

During polyelectrolyte adsorption using the PEM technique, a cationic and an anionic polyelectrolyte was used. The cationic polyelectrolyte was a cationic potato starch, Perlbond 980 S, with DS 0.065, from Lyckeby Stärkelsen AB, Sweden. The anionic polyelectrolyte was carboxymethyl cellulose (CMC), Cekol 50000 G, obtained from Noviant, Finland. The degree of substitution in the product was 0.8 and the molecular weight was approximately 900 000. The high-purity CMC, > 99.5\% pure, was dispersed in deionised water at a concentration of $1 \mathrm{~g} / \mathrm{L}$ and allowed to dissolve for $12 \mathrm{~h}$ before use.

\section{Fibre analysis}

The water retention value and drainability (SR number) were determined in accordance with the SCAN-C 62:00 and ISO 5267-1 methods, respectively. The length-weighted average fibre length and shape factor were determined in non-dried pulp samples, using a FiberMaster optical fibre analyser (Karlsson 1999). The pulp was defibrated in cold water, according to the SCAN-C 18:65 method, before analysis. The results for each sample were based on data from approximately 10000 fibres. Fibres were defined as particles with a length/width ratio greater than 4 . The definition of the shape factor is the projected fibre length divided by the true fibre length, i.e., a completely straight fibre has a shape factor of $100 \%$. 


\section{Determination of the pulp charge}

The charge of the fibres will influence the degree of fibre swelling and the ability of the fibres to adsorb charged polyelectrolytes. It was therefore necessary to determine the surface charge of the fibres. This was done using the polyelectrolyte titration method outlined in Wågberg et al. (1988); a high-molecular-weight $\left(1.2 \cdot 10^{6}\right)$ polyDMDAAC (poly(dimethyldiallyl-ammonium)chloride) was used in these measurements. The total charge of the fibres was determined using the conductometric titration method as outlined by Katz et al. (1984)

\section{Establishment of adsorptions isotherms}

Adsorption isotherms were determined at a fibre concentration of $5 \mathrm{~g} / \mathrm{L}$ in $0.01 \mathrm{M} \mathrm{NaCl}$ at $\mathrm{pH}$ 6. To a series of at least five $100-\mathrm{mL}$ samples, different amounts of polymer were added. The anionic CMC solutions were titrated with Polybrene (poly(1.5-dimethyl-1.5-diazaundeca-methylene)bromide) and the cationic starch solutions were titrated with KPVS (potassium polyvinyl sulphonate) to the isoelectric end point. The samples were then stirred for $10 \mathrm{~min}$ to reach adsorption equilibrium. The suspensions were then filtered using a Büchner funnel fitted with no. 3 filter paper (Munktell Filter, Grycksbo, Sweden). The clear filtrate was collected and the amount of polymer remaining in solution determined using a polyelectrolyte titrator (Mütek $\mathrm{GmbH}$, Germany) according to the method outlined in Wågberg and Ödberg (1988). The results of these experiments were then used to calculate the adsorption isotherms of all three pulps, corresponding to different degrees of energy consumption, for each layer.

Before the next layer of polyelectrolyte was added, the excess polymer in the previous layer was removed by filtration with a Büchner funnel. To remove the unabsorbed polymer, the filter pad was also washed with a small amount of distilled water.

\section{Preparation of PEM on fibres}

The pulps were diluted in deionised water to a solids concentration of $0.2 \%$. The salt concentration was adjusted to $0.01 \mathrm{M}$ by the addition of $\mathrm{NaCl}$, and the $\mathrm{pH}$ was fixed at 6 by adjustment with $\mathrm{HCl}$. Only half of each type of pulp was treated with the polyelectrolytes; the treated pulp was then mixed with the rest of the pulp before sheet preparation. Treatment of just a part of the furnish was made, mainly because earlier investigations had shown great benefits from such a strategy, which increased the strength properties of sheets at a low concomitant increase in density (Pettersson et al. 2006). Cationic starch was first adsorbed, followed by a treatment with CMC, and then finally with starch. Each polyelectrolyte was allowed to adsorb for $10 \mathrm{~min}$ while the fibre suspension was stirred. After multilayer treatment and mixing the different pulps, the fibre suspension was transferred to the sheet preparation equipment. Sheets were made from furnishes, where 50 $\%$ of the pulp was treated either with 1 layer of starch or $3 \mathrm{PEM}$ at $\mathrm{pH}$ 6.0. For each pulp type, one batch with one layer of starch and one batch with three PEM
(starch-CMC-starch) were produced. A common reference batch was also produced for each pulp type that was not treated with polyelectrolytes.

\section{Sheet preparation and testing}

Sheets were prepared according to the ISO5269-1 method and the physical properties of the paper were tested according to SCAN-P 67:93 and Scott-Bond was tested according to Tappi 833 pm-94. Freely dried sheets were also produced in order to more closely simulate paper made under industrial sack paper drying conditions. The freely dried sheets were made by hand, in the same was as the ordinary ISO sheets until the point of stacking. The stack was created as follows: a pressing plate was placed at the bottom, followed by two dry blotters, a couching blotter, the laboratory sheet, and then three dry blotters. This sequence was repeated for each laboratory sheet, and finally a second pressing plate was placed on top of the stack. The sheets were pressed at $490 \mathrm{kPa} \pm 10 \mathrm{kPa}$ for $4 \mathrm{~min} \pm 15 \mathrm{~s}$, then all the blotters were removed and the sheets were dried between Teflon wires on a drying drum. The temperature was $60 \pm 5^{\circ} \mathrm{C}$ and the drying time was approximately $2 \mathrm{~h}$.

The ISO sheets were pressed in a stack consisting of dry blotter, couch blotter and a laboratory sheet with drying plate, repeated several times. The stack was pressed at $410 \mathrm{kPa} \pm 10 \mathrm{kPa}$ for $5 \mathrm{~min} \pm 15 \mathrm{~s}$. A second pressing was carried out for which the order of the laboratory sheets was reversed and all the blotters were replaced, the stack was pressed again at $410 \mathrm{kPa} \pm 10 \mathrm{kPa}$ for $2 \mathrm{~min} \pm 15 \mathrm{~s}$. The drying plates with the laboratory sheets were then separated from the blotters and dried in a conditioned cabinet. The laboratory sheets were attached to the drying plates during drying to prevent them from shrinkage.

\section{Results and Discussion}

\section{Fibre characteristics}

Some of the results of measuring fibre properties after $\mathrm{HC}_{\text {atm }}$ or $\mathrm{HC}_{\text {press }}$ refining and $\mathrm{LC}$ refining are summarized in Table 1. As can be seen in this table, the higher the temperature during $\mathrm{HC}$ refining, the more LC energy was needed to reach a certain level of drainability. $\mathrm{The} \mathrm{HC}_{\text {press }}$, ${ }_{175}$ refined pulp was unfortunately beaten to a somewhat higher SR then the two other pulps in the investigation. Average fibre length is higher in the $\mathrm{HC}_{\mathrm{atm}}$ refined pulp than in the $\mathrm{HC}_{\text {press, }}$, 125 refined pulp, which in turn is higher than in the $\mathrm{HC}_{\text {press }}$, 175 refined pulp. Fibre shortening in the LC stage in $\mathrm{HC}_{\text {press }}$, 175 refined pulp was probably dependent on the higher energy input needed to obtain the desired SR level.

The water retention value was higher for the $\mathrm{HC}_{\mathrm{atm}}$ refined pulp sample than for the $\mathrm{HC}_{\text {press }},{ }_{125}$ refined pulp sample, which in turn had a higher WRV than the $\mathrm{HC}_{\text {press, }}, 175$ refined pulp sample. This difference must have already been achieved during the $\mathrm{HC}_{\text {atm }}$ or $\mathrm{HC}_{\text {press }}$ refining stage, because WRV increased upon LC refining and the pulp with the lowest WRV had the highest energy consumption in the LC refining stage. This indicates that 
Table 1. Pulp data from $\mathrm{HC}_{\text {atm }}$ or $\mathrm{HC}_{\text {press }}$ refining and subsequent $\mathrm{LC}$ refining.

\begin{tabular}{|c|c|c|c|c|c|c|c|c|}
\hline $\begin{array}{l}\text { Refining } \\
\text { condition } \\
{ }^{\circ} \mathrm{C}\end{array}$ & $\begin{array}{c}\text { HC energy } \\
\text { consumption } \\
\text { kWh/t }\end{array}$ & $\begin{array}{c}\mathrm{LC} \\
\text { refining } \\
\text { energy } \\
\mathrm{kWh} / \mathrm{t}\end{array}$ & SR & $\begin{array}{l}\text { Average } \\
\text { fibre } \\
\text { length } \\
\mathrm{mm}\end{array}$ & $\begin{array}{c}\text { Average } \\
\text { shape } \\
\text { factor } \\
\%\end{array}$ & $\begin{array}{c}\text { Water } \\
\text { retention } \\
\text { value } \\
\mathrm{g} \mathrm{H}_{2} \mathrm{O} / \mathrm{g} \text { fibre }\end{array}$ & $\begin{array}{c}\text { Total } \\
\text { charge } \\
\mu \mathrm{eq} / \mathrm{g}\end{array}$ & $\begin{array}{r}\begin{array}{r}\text { Surface } \\
\text { charge }\end{array} \\
\mu \mathrm{eq} / \mathrm{g}\end{array}$ \\
\hline $\mathrm{HC}_{\text {atm }}$ & 415 & 11 & 17.5 & 2.25 & 85.7 & 1.66 & 115 & 16 \\
\hline $\mathrm{HC}_{\text {press }}, 125$ & 353 & 46 & 17.5 & 2.16 & 86.6 & 1.61 & 115 & 16 \\
\hline $\mathrm{HC}_{\text {press }}, 175$ & 376 & 91 & 20.5 & 1.94 & 87.6 & 1.55 & 114 & 18 \\
\hline
\end{tabular}

some hornification of the fibres occurred in $\mathrm{HC}_{\text {press }}$ refining systems. Hornification is an irreversible decrease of fibre swelling capacity, which mainly occurs during drying.

\section{Charge determination of the different pulps}

To characterise the ability of the different fibres to interact with the polyelectrolytes, fibres were subjected to conductometric titration and their surface charge was determined by polyelectrolyte adsorption. The results of these measurements are also shown in Table 1.

The fibre surface charge after LC refining was somewhat higher in the $\mathrm{HC}_{\text {press }}$, 175 refined pulp than in the two other pulp samples, even though the WRV values indicate that the pulp wS less swollen, which means that the pores should be less accessible to polyelectrolytes. This increase in fibre surface charge could be because of a higher degree of external fibrillation and a larger surface area, due to micro compressions occurring in the LC refiner for the $\mathrm{HC}_{\text {press } 175}$ refined pulp. The external fibrillation made a larger surface area accessible to the polyelectrolytes. The total charge of the fibres was almost equal for all the pulp samples, as expected. The surface charge was approximately $14 \%$ of the total charge for the $\mathrm{HC}_{\text {atm }}$ and the $\mathrm{HC}_{\text {press, }},{ }_{125}$ refined pulps, while it was roughly $16 \%$ for the $\mathrm{HC}_{\text {press }}$, 175 refined pulp. This also suggests that the polymer was able to reach more charges than just those on the external fibre surface. It is also possible that a larger than normal external surface area was opened up because of external fibrillation.

\section{Adsorption isotherms of the polyelectrolytes}

The adsorption isotherms of the $\mathrm{HC}_{\text {atm }}$ refined pulp are shown in Fig 1. Analogous to the method used for determining surface charge, the total amount of adsorbed polymer was derived by extrapolating the adsorption isotherm to zero concentration, as shown by the dotted lines in Fig 1. Since there is no clear levelling off in these diagrams this extrapolation has to be viewed upon as an attempt to secure a reasonable addition level for the subsequent polymer treatment. Since there was a rinsing step between the layers the excess polymer was removed. Adsorption isotherms for $\mathrm{HC}_{\text {press }}$ refined pulps were determined in the same way. The adsorbed amount of polymer in each layer is summarized in Table 2. The adsorbed amount of starch in the first layer was higher in the $\mathrm{HC}_{\text {press }},{ }_{175}$ refined pulp sample than in the other two pulp samples, which adsorbed almost equal amounts of starch. This was expected, because the surface charge was higher in the $\mathrm{HC}_{\text {press, }}, 175$ refined pulp sample. The results of the second and third layer measurements showed the same trend. Assuming a 1:1 stoichiometry between the starch and the fibre charges, one can calculate that the starch could reach approximately $12 \%$ of the total charges on the $\mathrm{HC}_{\text {atm }}$ and the $\mathrm{HC}_{\text {press, }}$, ${ }_{125}$ refined pulps, and approximately $14 \%$ on the $\mathrm{HC}_{\text {press }}$, 175 refined pulp sample. The starch reached fewer charges than did the polyDMDAAC used for surface charge determination, probably due to the higher molecular mass of the starch. The lower adsorption of starch in the third layer suggest to us that that not all the charges of the starch in the first layer were available for interaction with $\mathrm{CMC}$ in the subsequent layer. It has been shown (Decher and Schlenoff 2003, and Wågberg et al. 2004) that the charge balance between the polyelectrolytes can be reduced at higher layer numbers.

\section{Airflow resistance}

For each pulp sample, one batch with one layer of starch and one batch with three PEM were produced. Airflow resistance for the three series of sheets produced can be found in Table 3. All airflow resistance values lied between 0.4 and $1.9 \mathrm{~s}$, which can be classified as very low. This is interesting and important, since one aim of this research was to produce a high-strength sheet with low air resistance.

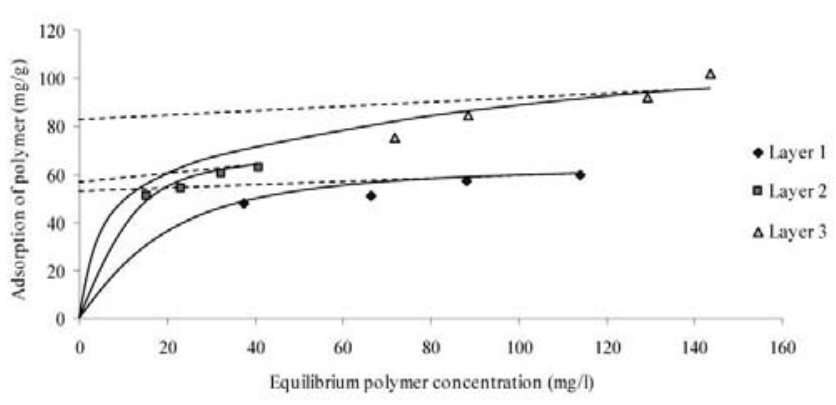

Fig 1. Adsorption curves for the $\mathrm{HC}_{\text {atm }}$-refined pulp. The equilibrium concentration of the polymer is a function of the total adsorbed amount of polymer. The total amount of adsorbed polymer is derived by extrapolating the adsorption isotherms to zero concentration, as shown by the dotted lines.

Table 2. Adsorbed amount of polymers on fibres

\begin{tabular}{lccc}
\hline \multicolumn{1}{c}{ Refining condition } & $\begin{array}{c}\text { Layer 1 } \\
\text { (Starch) } \\
\mathbf{m g} / \mathbf{g}\end{array}$ & $\begin{array}{c}\text { Layer 2 } \\
\text { (Starch-CMC) } \\
\mathbf{m g} / \mathbf{g}\end{array}$ & $\begin{array}{c}\text { Layer 3 } \\
\text { (Starch-CMC-Starch) } \\
\mathbf{m g} / \mathbf{g}\end{array}$ \\
\hline $\mathrm{HC}_{\text {atm }}$ & 53 & 3 & 26 \\
$\mathrm{HC}_{\text {press, } 125}$ & 52 & 3 & 25 \\
$\mathrm{HC}_{\text {press, } 175}$ & 60 & 4 & 33 \\
\hline
\end{tabular}

Table 3. Airflow resistance (s/100 mL, Gurley) of ISO and freely dried sheets at different starch layers.

\begin{tabular}{lccc}
\hline $\begin{array}{l}\text { Refining condition } \\
{ }^{\circ} \mathrm{C}\end{array}$ & $\begin{array}{c}\text { Reference } \\
\text { (Starch) }\end{array}$ & $\begin{array}{c}\text { 1 Layer } \\
\text { (Starch- CMC- Starch) }\end{array}$ & Layer 3 \\
\hline ISO sheets & & & \\
$\mathrm{HC}_{\text {atm }}$ & 1.3 & 1.1 & 1.2 \\
$\mathrm{HC}_{\text {press, } 125}$ & 0.9 & 0.4 & 1.0 \\
$\mathrm{HC}_{\text {press, } 175}$ & 1.2 & 0.7 & 0.9 \\
Freely dried sheets $_{H C_{\text {atm }}}$ & 1.0 & & \\
$\mathrm{HC}_{\text {press, } 125}$ & 1.0 & 0.6 & 1.3 \\
$\mathrm{HC}_{\text {press, }, 175}$ & 1.9 & 0.4 & 0.9 \\
\hline
\end{tabular}




\section{Strength of sheets prepared with Starch/CMC multilayer treatment on ISO sheets}

Previously published results (Pettersson et al. 2006) regarding the treatment of mixtures of chemimechanical pulps and chemical pulps have shown that there were great advantages of using PEM treatment to enhance paper strength. In Figs 2-5, the strength properties of ISO sheets made of the pulps manufactured under different refining conditions in the $\mathrm{HC}$ stage and with additional PEM treatments are shown. The treatments correspond to the addition of starch and CMC in different layers, and the properties of the reference untreated pulps are shown as well.

Fig 2 shows the influence of the treatment of the different pulp samples on strain-at-break properties as a function of density. Strain at break was enhanced when one layer of starch was added to all the different pulps, but remained constant or decreased somewhat when two more layers were added to the fibres.

Figs 3 and 4 show the effects of PEM treatment on the tensile index and tensile energy absorption of the sheets. Addition of further layers left the tensile index relatively unaffected. As seen in Fig 4, the tensile energy adsorption results followed a similar pattern: one layer of polymer added to the pulp improved the tensile energy adsorption by approximately $50-70 \%$ compared to that of the reference, while the tensile index was unchanged or even worsened by adding two more layers of polymer. The results for the Scott-bond values indicated totally different trends, as shown in Fig 5. The Scott-bond value rose considerably from that of the reference when the first polymer layer was added, and was improved even further when three polymer layers were added.

Figs 2-5 show that PEM addition resulted in large dry strength improvements in the out-of-plane properties measured as Scott-bond. Tensile index, strain at break, and tensile energy absorption index were improved as much by adding just one layer of starch to the fibre surface. As mentioned earlier, the increase in strength may have been caused either by strengthening the fibre wall or increasing the joint strength between the fibres. It is of course difficult to draw any final conclusions from the present results, but the results give an interesting indication that the fibre strength was too low in the case of $\mathrm{HC}$ refined pulp to achieve the full benefit from PEM treatment. It should be added that fibre flocculation is sometimes a problem in laboratory evaluation of strength additives but in the present work no ocular differences in formation of the treated and untreated sheets could be detected.

\section{Strength of sheets prepared with Starch/CMC multilayer treatment on freely dried sheets}

Figs 2-5 show different strength properties of freely dried sheets made from the same pulps and using the same treatments as described in the previous section. Again, the improvement in Scott-bond was the most significant change for all pulps, and the PEM treatment with three layers produced much greater improvements than just one layer. The results indicate that $\mathrm{HC}_{\text {press }}$, ${ }_{175}$ refined pulp improved its Scott-bond value considerably with the

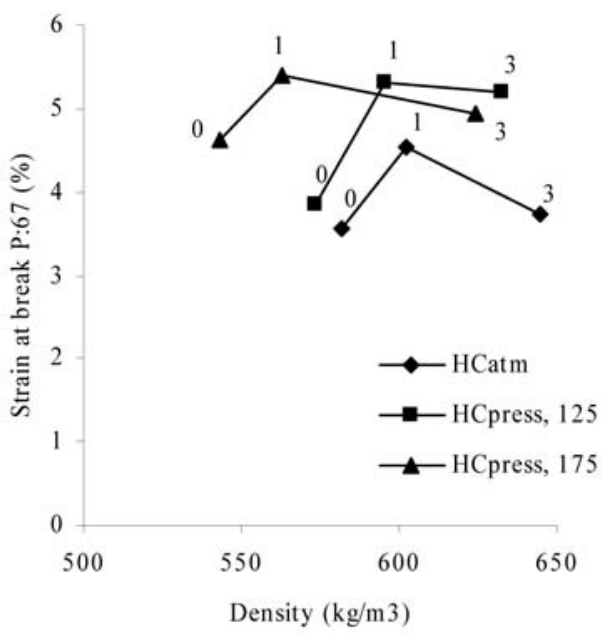

Fig 2. The effect of adding multilayers to $\mathrm{HC}_{\text {atm }}$ - or $\mathrm{HC}_{\text {press }}$-refined and subsequently LC-refined pulp on strain at break, versus density, for ISO sheets. The numbers included in the figure refer to the number of treatments with starch or starch and CMC. $(0=$ ref, 1 = starch, $3=$ starch-CMC-starch).

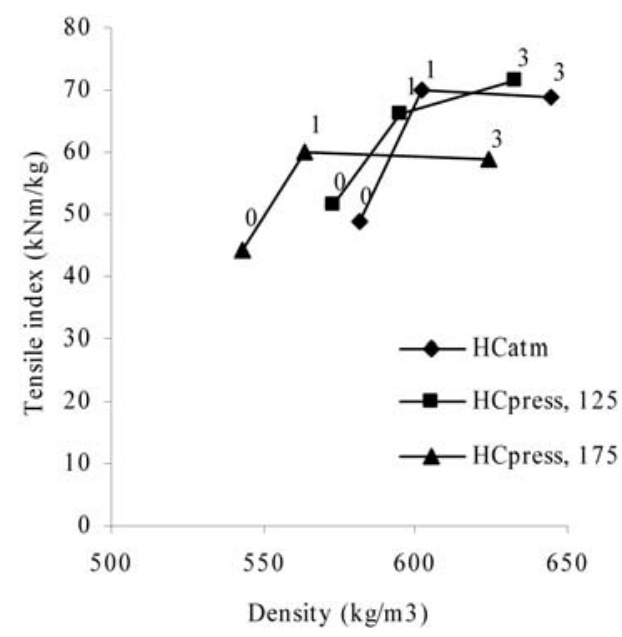

Fig 3. The effect of adding multilayers to $\mathrm{HC}_{\text {atm }}$ - or $\mathrm{HC}_{\text {press }}$-refined and subsequently LC-refined pulp on tensile index, versus density, for ISO sheets. The numbers included in the figure refer to the number of treatments with starch or starch and CMC. $(0=$ ref, $1=$ starch, $3=$ starch-CMC-starch).

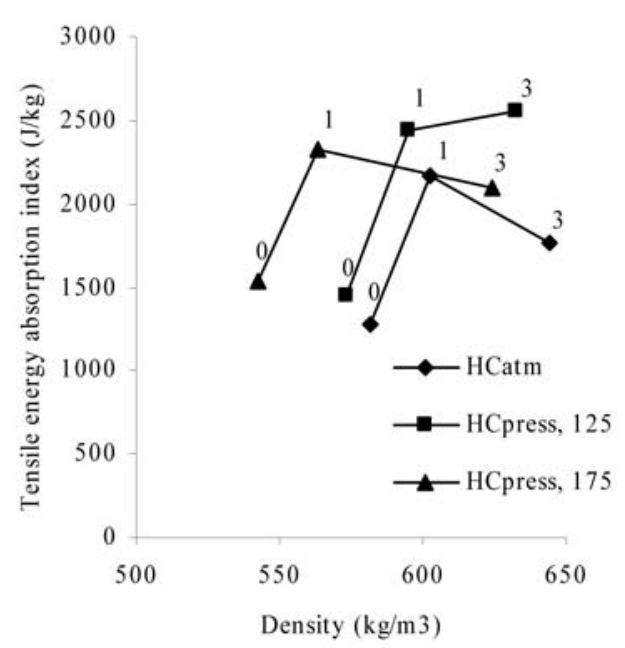

Fig 4. The effect of adding multilayers to $\mathrm{HC}_{\text {atm }}$ or $\mathrm{HC}_{\text {press }}$-refined and subsequently LC-refined pulp on tensile energy absorption index, versus density, for ISO sheets. The numbers included in the figure refer to the number of treatments with starch or starch and CMC. (0 = ref, 1 = starch, $3=$ starch-CMC-starch). 


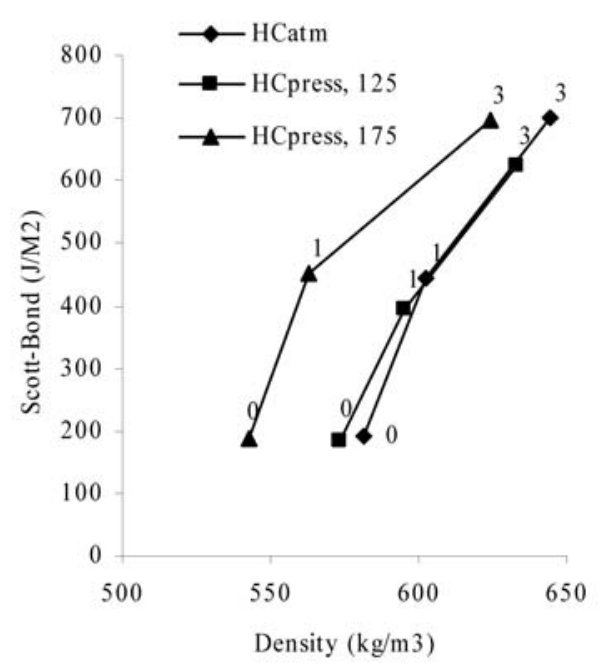

Fig 5. The effect of adding multilayers to $\mathrm{HC}_{\text {atm }}$ or $\mathrm{HC}_{\text {press }}$-refined and subsequently LC-refined pulp on Scott-bond, versus density, for ISO sheets. The numbers included in the figure refer to the number of treatments with starch or starch and CMC. (0 = ref, 1 = starch, 3 = starch-CMC-starch).

addition of the first polymer layer, but less so with the addition of the next two layers. For the $\mathrm{HC}_{\mathrm{atm}}$ refined pulp the opposite was the case: little improvement was achieved after adding the first polymer layer, but with the addition of two more layers, the Scott-bond was increased significantly. One interesting result for the freely dried sheets is that the tensile index improved for all pulps with PEM treatment, which was not the case with the restrained-dried sheets. The reason for this difference is not known, but it indicates that how PEM treatment influences sheet strength can be traced back to the consolidation between fibres in the wet state.

For many papermakers, such as sack paper producers, the tensile energy absorption index is crucial. From the discussion in previous sections and the results presented in Figs 2-5, one can suggest that an $\mathrm{HC}_{\text {press }}$ refined pulp is recommended when high tensile energy absorption index values are demanded. The sheets should be allowed to shrink freely in order to maximize strain at break, thus increasing the tensile energy absorption index. The stock should also be subjected to some sort of polymer treatment.

\section{Comparison between free and restrained drying of ISO sheets prepared with the multilayer technique}

The results shown in Figs 2-5 indicate that there was a difference in the effect of the polyelectrolytes on sheets that were dried under free or restrained conditions. A closer comparison of these differences was therefore of considerable interest. Figs 6, 7, 8, and 9 show the effect of the different sheet drying methods when there were three layers of additives on the fibres, i.e., two layers of cationic starch and one layer of CMC. Fig 6 shows how the tensile index decreased with the addition of a third layer in the ISO sheets, whereas it increased in the freely dried sheets. It should also be noted that the density increased significantly with the addition of the third layer in both ISO sheets and freely dried sheets, but that the strength was only enhanced in the freely dried sheets (except for one of the pulps). Figs 7 and 8 show the

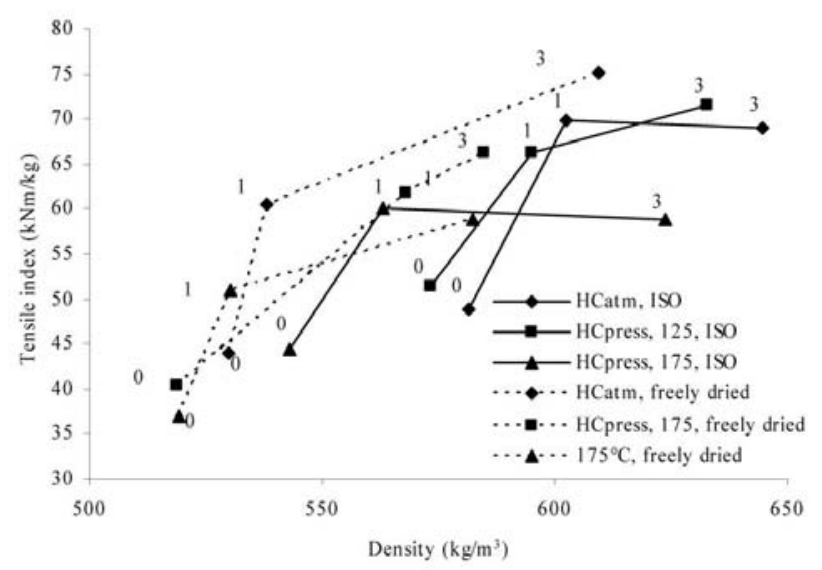

Fig 6. The effect of adding multilayers to $\mathrm{HC}_{\text {atm }}$ - or $\mathrm{HC}_{\text {press }}$-refined pulp on tensile index, versus density, for ISO sheets and freely dried sheets. The numbers included in the figure refer to the number of treatments with starch or starch and CMC. $(0=$ ref, 1 = starch, $3=$ starch-CMC-starch).

tensile energy and strain at break, versus density, and almost the same tendency is evident. The freely dried sheets displayed increased tensile energy absorption, while the ISO sheets did not show the same improvement, especially not with the addition of the third layer.

The exact reason for the differences is not known but, possibly, the fibres and multilayers have different shrinkage behaviour during drying. If the multilayers shrink more than the fibres do as in the case in restrained drying, it is possible that the contact area between the fibres and the multilayers decreases due to the breakage of molecular contacts during drying. However, if the multilayers and the fibres shrink together, as they do during free drying, the contact points between the layers and fibres could possibly be preserved, leading to improved paper strength. Another explanation could be that the results can be expected to depend on whether paper failure is caused by (a) brittle behaviour, or (b) limiting joint strength. In the case of a more extensible fiber (due to unconstrained drying), there is less danger of brittle failure- therefore it makes sense that the system can accommodate a greater chemical enhancement of interfiber bonding. However, in the case of less extensible sheet (dried under constraint), any increase on the bonding strength can be expected to make the structure more brittle. The underlying idea of combining PEM treatment and free drying, which would be fairly suitable for conditions in a sack paper machine, was to increase the strain at break and the tensile index of the sheets, which would be ideal for strong sack paper. As shown in Fig 6, the tensile index of the freely dried paper made from $\mathrm{HC}_{\mathrm{atm}}$ refined pulp was increased from 42 to 75 with the addition of three PEM. At the same time, the strain at break was increased from $5.5 \%$ to close to $8 \%$ (see Fig 7), and together these improvements lead to an increase in tensile energy absorption index from 1600 $\mathrm{J} / \mathrm{kg}$ to $3500 \mathrm{~J} / \mathrm{kg}$, as shown in Fig 8. Similar effects were achieved with $\mathrm{HC}_{\text {press }}$ refined pulps. The final tensile energy absorption values were even higher under these refining conditions (see Fig 8). No doubt these improvements were substantial, but further research is still needed for final optimisation. 


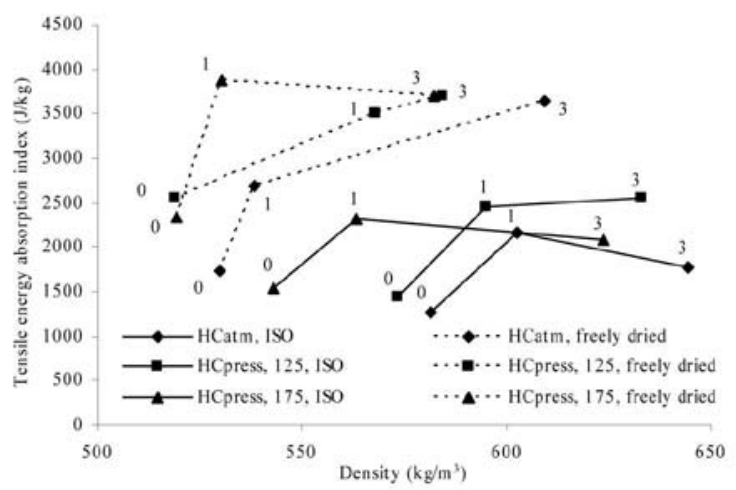

Fig 7. The effect of adding multilayers to $\mathrm{HC}_{\text {atm }}$ - or $\mathrm{HC}_{\text {press }}$-refined pulp on tensile energy absorption index, versus density, for ISO sheets and freely dried sheets. The numbers included in the figure refer to the number of treatments with starch or starch and CMC. $(0=$ ref, 1 = starch, $3=$ starch-CMC-starch).

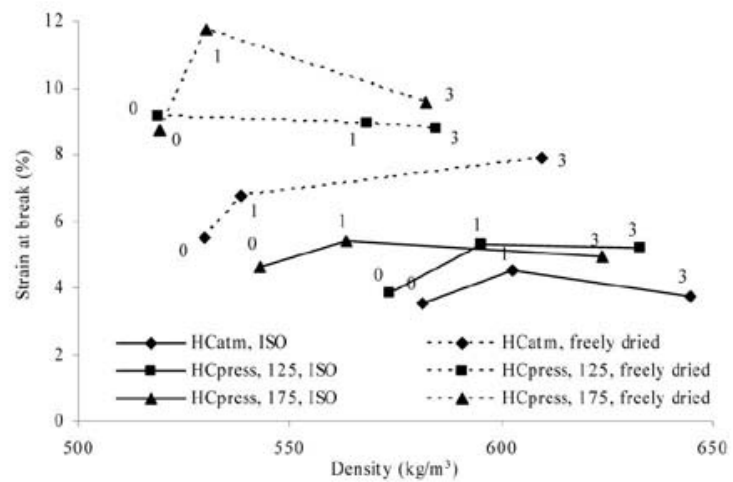

Fig 8. The effect of adding multilayers to $\mathrm{HC}_{\text {atm }}$ - or $\mathrm{HC}_{\text {press }}$-refined pulp on strain at break, versus density, for ISO sheets and freely dried sheets. The numbers included in the figure refer to the number of treatments with starch and CMC. (0 $=$ ref, 1 = starch, 3 = starch-CMC-starch)

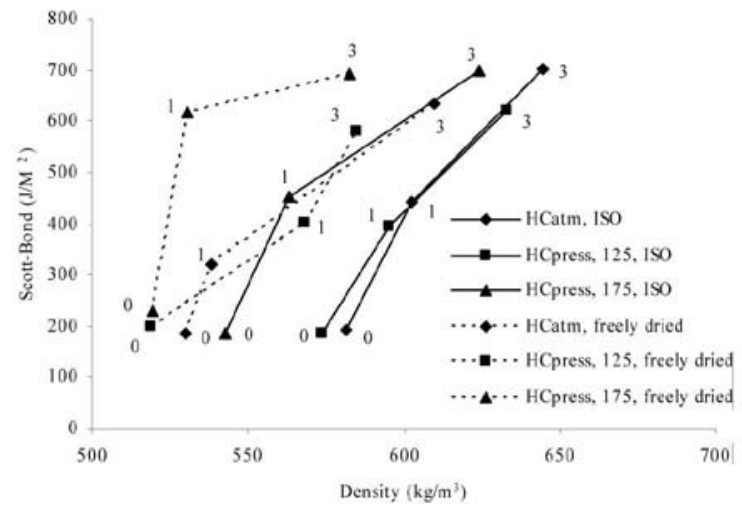

Fig 9. The effect of adding multilayers to $\mathrm{HC}_{\text {atm }}$ - or $\mathrm{HC}_{\text {press }}$-refined pulp on Scottbond, versus density, for ISO sheets and freely dried sheets. The numbers included in the figure refer to the number of treatments with starch and CMC. $(0=$ ref, 1 = starch, 3 = starch-CMC-starch).

The Scott-bond value improved greatly for free as well as restrained dried sheets from that of the reference when the first layer of polymer was applied, and values were enhanced still further when three layers of polymer were applied.

\section{Conclusions}

Polyelectrolyte multilayers (PEM), comprising cationic starch and anionic carboxymethyl cellulose, were applied to unbleached kraft pulp refined to a high consistency in either an atmospheric $\left(\mathrm{HC}_{\mathrm{atm}}\right)$ or a pressurized $\left(\mathrm{HC}_{\text {press }}\right)$ refiner at 125 or $175^{\circ} \mathrm{C}$, respectively. The pulp fibres from the $\mathrm{HC}_{\text {press }}$ refining system were more curled than those from the $\mathrm{HC}_{\mathrm{atm}}$ refining system. When the $\mathrm{HC}_{\mathrm{atm}}$ or $\mathrm{HC}_{\text {press }}$ refined pulp samples were subsequently $\mathrm{LC}$ refined in an Esher-Wyss refiner, the fibres became straightened. The WRV was higher for the pulp sample from the $\mathrm{HC}_{\mathrm{atm}}$ refining system than for those from the $\mathrm{HC}_{\text {press }}$ refining systems.

PEM treatment with starch and CMC adsorbed onto the fibres improved Scott-Bond values significantly compared to the use of only one layer of starch. This was the case for both the ISO and the freely dried sheets. ISO sheets made from the pulp that was $\mathrm{HC}_{\text {press }}$ refined at $175^{\circ} \mathrm{C}$, and to which three polymer layers were added, had a Scott-bond value almost $275 \%$ better than that of the reference. However, no major positive effects on strain at break, tensile index, or tensile energy absorption index values could be obtained in ISO sheets made from pulp with multiple polymer layers as compared to a single starch layer. The freely dried sheets, which were produced under conditions closer to those of a sack paper machine, were more positively influenced by multilayer treatment than the ISO sheets were. Tensile index and tensile energy absorption could be improved considerably in freely dried sheets when the sheets were made from multilayer treated pulp rather than from pulp with only one added layer of starch.

\section{Acknowledgements}

The authors thank Mondi Packaging Dynäs AB for supplying kraft pulp and also for their valuable knowledge of the production of sack paper. We would also like to thank the staff at SCA Graphic Research and at Metso R\&D Centre in Sweden for their assistance in this study. One of the rewires is also acknowledge for contributing explanations to some of the results.

\section{Literature}

Decher, G. and Schlenoff, J. (2003): Multilayer Thin Films: Sequential Assembly of Nanocomposite Materials, Weinheim, Germany, Wiley-VCH, 524 pp.

Decher, G. (1997): Fuzzy Nano-assemblies: Toward Layered Polymeric Multicomposites, Science, 277, 1233.

Gärdlund, L., Wågberg, L. and Gernandt R. (2003): Polyelectrolyte complexes for surface modification of wood fibres. Part II: Influence of complexes on wet and dry strength of paper, Colloids and Surfaces, 218, (137-149).

Hartler, N. (1995): Aspects on curled and microcompressed fibres, Nord. Pulp Paper Res. J. No. 1, 4-7.

Htun, M and de Ruvo, A. (1981): The influence of drying strategies on the relationship between drying shrinkage and strain to failure of paper. The Role of Fundamental Research in Papermaking Symposium, Vol 2, held September at Cambridge, 385-374.

Hubbe, M. (2005): Dry-strength development by polyelectrolyte complexes onto nonbonding glass fibres. J. Pulp Paper. Sci., 31, 4.

Karlsson, H., Fransson, P.I. and Molin, U.B. (1999): STFI FiberMaster, SPCI, 6 th International Conference on new available technologies. June 3, Stockholm.

Katz, S., Beatson, R.P. and Scallan, A.M. (1984): The determination of strong and weak acidic groups in sulphite pulps, Svensk Paperstidning, 87(6), R48.

Lindström, T., Wågberg, L. and Larsson, T. (2005): On the nature of joint strength in paper: a review of dry and wet strength resins used in paper manufacturing. Advances in Paper Science and Technology: 13th Fundamental Research Symposium, Cambridge, UK, Sept. 2005. 
Miller, P.R. (1998): Fibre and sheet properties resulting from refining stock consistency variation, Appita, Vol. 42, No. 2, March, 125-130.

Omholt, I. (1999): The Effects of Curl and Microcompressions on the Combination of Sheet properties. TAPPI International Paper Physics Conference, San Diego, CA USA, Sept. 499-515.

Page, D. H. (1971): The structure and properties of paper, Part II. Shrinkage, dimensional stability and stretch. This paper is reprinted from magazine TREND, No. 18, Spring, by permission of the Pulp and Paper Research Institute of Canada, 13-19.

Pettersson, G., Wågberg, L. and Höglund, H. (2006): The use of polyelectrolyte multilayers of cationic starch and $\mathrm{CMC}$ to enhance strength properties of papers formed from mixtures of bleached chemical pulp and CTMP. Part II: Influence of addition strategy, fibre treatment and fibre type, Nord. Pulp Paper Res. J. 21(1), 122.

Sandberg, S. and Andreasson, A. (2001): International patent application W0 01/77437 A1.

Sjöberg, J.C. and Höglund, H. (2005): Refining systems for sack paper pulp. Part I: HC refining under pressurised conditions and subsequent LC refining. Nord. Pulp Paper Res. J. 20(3), 320.

Vainio, A., Paulapuro, H., Koljonen, K. and Liana, J. (2006): The effect of drying stress and polyelectrolyte complexes on the strength properties of paper. J. Pulp Paper Sci. 31, 1.

Wahlström, T. (1999): Influences of Shrinkage and Stretch during Drying on Paper Properties, Licentiate Thesis, Stockholm, Department of Pulp and Paper
Chemistry and Technology, Royal Institute of Technology, Stockholm, Sweden. Wågberg, L. (2000): Polyelectrolyte adsorption onto cellulosic fibres review, Nord. Pulp Paper Res. J. 15(5), 586.

Wågberg, L., Forsberg, S., Johansson, A. and Juntti, P. (2002): Engineering of fibre surface properties by application of the polyelectrolyte multilayer concept. Part I: Modification of paper strength, J. Pulp Paper Sci. 28, 222.

Wågberg, L. and Kolar, K. (1996): Adsorption of cationic potato starch on cellulosic fibers, Nord. Pulp Paper Res. J. 8(4), 399.

Wågberg, L., Pettersson, G. and Notley, S. (2004): Adsorption of bilayers and multilayers of cationic and anionic co-polymers of acrylamide on silicon oxide, J. Colloid Interface Sci. 274(2), 480.

Wågberg, L., Ödberg, L. and Glad-Nordmark, G. (1988): Charge determination of porous substrates by polyelectrolyte adsorption. Part 1: Carboxymethylated bleached cellulosic fibres. Paper presented at Swedish Pulp and Paper Research Institute (STFI), Paper Chemistry Symposium 1988, 27-29 Sept. 1988, Stockholm, Sweden.

Wågberg, L. and Ödberg, L. (1988): Short introduction to the art of polyelectroIyte titration, STFI message A982.

Zheng, Z., McDonald, J., Khillan, R., Su, Y., Shutava, T., Grozdits, G and Lvov, Y. (2006): Layer-by-layer nanocoating of lignocellulose fibres for enhanced paper properties. J. Nanoscience Nanotechnology, 6(3).

Manuscript received 16 Oktober, 2006 Accepted January 19, 2007 